Internat. J. Math. \& Math. Sci.

Vol. 23, No. 11 (2000) 783-788

S0161171200003057

(C) Hindawi Publishing Corp.

\title{
EXISTENCE AND UNIQUENESS THEOREMS FOR SOME FOURTH-ORDER NONLINEAR BOUNDARY VALUE PROBLEMS
}

\author{
RUYUN MA
}

(Received 30 March 1998)

ABSTRACT. Let $G$ and $f:[0,1] \times \mathbb{R}^{4} \rightarrow \mathbb{R}$ be two functions satisfying Caratheodory conditions. This paper is concerned with the problems of existence and uniqueness of solutions for the nonlinear fourth-order ordinary differential equation

$$
y^{\prime \prime \prime \prime}+\lambda y^{\prime \prime}+k y+G\left(x, y, y^{\prime}, y^{\prime \prime}, y^{\prime \prime \prime}\right)=f\left(x, y, y^{\prime}, y^{\prime \prime}, y^{\prime \prime \prime}\right)
$$

with one of a particular set of boundary conditions.

Keywords and phrases. Fourth-order BVP, solution, Leray-Schauder fixed point theorem, homogeneous nonlinearity.

2000 Mathematics Subject Classification. Primary 34B15.

1. Introduction. In this paper, we are concerned with the global solvability of the fourth-order ordinary differential equation

$$
y^{\prime \prime \prime \prime}+\lambda y^{\prime \prime}+k y+G\left(x, y, y^{\prime}, y^{\prime \prime}, y^{\prime \prime \prime}\right)=f\left(x, y, y^{\prime}, y^{\prime \prime}, y^{\prime \prime \prime}\right)
$$

with one of the following sets of boundary conditions:

$$
\begin{aligned}
& y(0)=y^{\prime \prime}(0)=y(1)=y^{\prime \prime}(1)=0 ; \\
& y(0)=y^{\prime \prime}(0)=y(1)=y^{\prime}(1)=0 ; \\
& y(0)=y^{\prime \prime}(0)=y^{\prime}(1)=y^{\prime \prime \prime}(1)=0 ; \\
& y(0)=y^{\prime}(0)=y(1)=y^{\prime}(1)=0 ; \\
& y(0)=y^{\prime}(0)=y^{\prime \prime}(1)=y^{\prime \prime \prime}(1)=0 ; \\
& y(0)=y^{\prime}(0)=y^{\prime}(1)=y^{\prime \prime \prime}(1)=0 .
\end{aligned}
$$

(Hereinafter, for simplicity, when we refer to (1.1) we will actually mean the fourthordinary differential equation (1.1) along with one of the boundary conditions given in (1.2) through (1.7).) Those boundary value problems govern the equilibrium states of a beam-column. The source of nonlinearity comes from a nonlinear lateral constraint (foundation). The equilibrium equation is formulated as a fourth-order nonlinear differential equation. Different boundary conditions are corresponding to various ways in which the ends of the beam may be supported.

Very recently, Elgindi and Guan [3] studied these boundary value problems when $G$ in (1.1) is independent of $y^{\prime \prime \prime}$, and $f$ in (1.1) is independent of $y, y^{\prime}, y^{\prime \prime}$, and $y^{\prime \prime \prime}$, that is, $G\left(x, y, y^{\prime}, y^{\prime \prime}, y^{\prime \prime \prime}\right)=G\left(x, y, y^{\prime}, y^{\prime \prime}\right)$ and $f\left(x, y, y^{\prime}, y^{\prime \prime}, y^{\prime \prime \prime}\right)=f(x)$. It turns 
out that the dependence of $G$ and $f$ in (1.1) on the third-order derivative $y^{\prime \prime \prime}$ of $y$ causes a fundamental difference between the problem studied in this paper and the corresponding problems studied in [3], where $G$ and $f$ are independent of $y^{\prime \prime \prime}$. The conditions on $G\left(x, y, y^{\prime}, y^{\prime \prime}\right)$ for the existence of a solution to the boundary value problems (1.1), as given in [3], are some homogeneous conditions and sign conditions with respect to $y$. Now when $G$, in (1.1), is not independent of $y^{\prime \prime \prime}$, these conditions on $G$ which are related to $y$ do not give the necessary, a priori, estimates to obtain existence of a solution to the boundary value problems (1.1). It is the purpose of this paper to show that necessary, a priori, estimates can be obtained to prove existence of a solution to the boundary value problems (1.1) when one imposes conditions on $G$ and $f$ they are related to $y^{\prime \prime \prime}$. We remark that the existence and uniqueness theorems obtained in this paper for the boundary value problems (1.1), when particularized to the case when $G$ in (1.1) is independent of $y^{\prime \prime \prime}$ and $f\left(x, y, y^{\prime}, y^{\prime \prime}, y^{\prime \prime \prime}\right)=f(x)$ gives new existence theorems for the problems studied in [3]. We would like to refer the reader to $[1,2,4,5,6,7,8]$ and references therein for related works on fourth-order boundary value problems.

The proof of the existence of solutions is based upon a corollary of Leray-Schauder fixed point theorem, which we state here as the following lemma.

LEMMA 1.1. Let $B$ be a banach space and $K: B \rightarrow B$ be a compact operator. Suppose that there exists a priori bound $m>0$ such that every solution of $y-t K y=0$, for $t \in[0,1]$, satisfies $\|y\| \leq m$. Then $K$ has a fixed point $y$ with $\|y\| \leq m$.

\section{Assumptions and preliminary results}

DEFinition 2.1. A function $u:[0,1] \times \mathbb{R}^{k} \rightarrow \mathbb{R}$ is said to satisfy Corotheodory's condition for $L^{q}(0,1)$ if the following conditions are satisfied:

(i) for a.e. $x \in[0,1]$, the function $f(x, \cdot)$ is continuous;

(ii) for every $y \in R^{k}$, the function $f(\cdot, y)$ is measurable;

(iii) for every $r>0$, there is $g_{r} \in L^{q}(0,1)$ such that for a.e. $x \in[0,1],|u(x, y)| \leq$ $g_{r}(x)$ whenever $\|y\| \leq r$.

Throughout the rest of the paper, we use the following notation:

$$
\begin{gathered}
W^{k}=\left\{y:[0,1] \longrightarrow \mathbb{R} \mid y^{(j)} \in A C[0,1], j=0,1, \ldots, k-1 \text { and } y^{(k)} \in L^{2}(0,1)\right\}, \\
\|y\|_{k}^{2}=\sum_{j=0}^{k}\left\|y^{(j)}\right\|_{k}^{2}, \quad y \in W^{k},
\end{gathered}
$$

$D\left(L_{i}\right)=\left\{y \in W^{k} \mid y\right.$ satisfies the $i$ th boundary conditions $\left.(1 . i)\right\}, i=2, \ldots, 7$,

$L_{j}: D\left(L_{i}\right) \rightarrow L^{2}(0,1)$ is defined by

$$
L_{j}(y)=y^{\prime \prime \prime \prime} .
$$

We make the following assumptions.

(H1) Let $f:[0,1] \times \mathbb{R}^{4} \rightarrow \mathbb{R}$ satisfy Corotheodory's condition for $L^{2}(0,1)$ and there exists $\bar{f} \in L^{2}(0,1)$ such that

$$
|f(x, y, z, u, v)| \leq \bar{f}(x) \text { for all }(x, y, z, u, v) \in[0,1] \times R^{4} .
$$


(H2) $G(x, y, z, u, v)=g(u)+h(x, y, z, u, v)$, where $g$ is continuous, $h:[0,1] \times \mathbb{R}^{4} \rightarrow \mathbb{R}$ satisfies Corotheodory's condition for $L^{2}(0,1)$. (It is well known that the map $H$ : $[0,1] \times W^{3} \rightarrow L^{2}(0,1)$ defined by $H(x, y)=h\left(x, y, y^{\prime}, y^{\prime \prime}, y^{\prime \prime \prime}\right)$ is continuous.) Furthermore, we assume

(a) there exists $p>1$ such that

$$
g(r u)=r^{p} g(u) \quad \text { for } r, x \in R \text { with } r>0 ;
$$

(b) for any $y \in W^{3}, \int_{0}^{1} g\left(y^{\prime \prime}\right) y^{\prime \prime} d x \leq 0$, and $\int_{0}^{1} g\left(y^{\prime \prime}\right) y^{\prime \prime} d x=0$ if and only if $y^{\prime \prime}=0$

(c) $\int_{0}^{1} h(x, y, z, u, v) u d x \leq 0, y \in W^{3}$.

We collect some preliminary results which we use in Section 3 in the following lemmas.

LEMmA 2.2. If $u \in C^{1}[0,1]$, and $u(0)=0$, then $\|u\|_{L^{2}}^{2} \leq\left(4 / \pi^{2}\right)\left\|u^{\prime}\right\|_{L^{2}}^{2}$.

LEMMA 2.3. If $u \in C^{1}[0,1]$, and $u(0)=0=u(1)$, then $\|u\|_{L^{2}}^{2} \leq\left(1 / \pi^{2}\right)\left\|u^{\prime}\right\|_{L^{2}}^{2}$.

LEMMA 2.4. Let $M_{\eta}=\max \{\eta, 1-\eta\}, 0 \leq \eta \leq 1$. If $u \in C^{1}[0,1]$, and $u(\eta)=0$, then

$$
\|u\|_{L^{2}}^{2} \leq\left(\frac{4}{\pi^{2}}\right) M_{\eta}\left\|u^{\prime}\right\|_{L^{2}}^{2} .
$$

Lemmas 2.2 and 2.3 are direct consequences of Wirtinger's inequalities, see [1]. Lemma 2.4 can be easily deduced from Lemmas 2.2 and 2.3.

LEMMA 2.5. For each $L_{j}, j=2, \ldots, 7$, the following are true:

(A) $L_{j}$, as an operator on $L^{2}$, is densely defined and self-adjoint;

(B) $c_{j}\|y\|_{L^{2}} \leq\left\|y^{\prime \prime}\right\|_{L^{2}} \leq d_{j}\left\|y^{\prime \prime \prime}\right\|_{L^{2}}$ for $y \in D\left(L_{j}\right)$, where $c_{2}=c_{5}=\pi^{2}, c_{3}=c_{7}=$ $\pi^{2} / 2, c_{4}=c_{6}=\pi^{2} / 4 ; d_{2}=1 / \pi, d_{3}=d_{4}=d_{5}=d_{6}=d_{7}=2 / \pi$

(C) for any $y \in D\left(L_{j}\right), L_{j} y=0$ if and only if $y=0$;

(D) there exists unique $\psi_{j}: L^{2}(0,1) \rightarrow W^{4}$ such that $L_{j}\left(\psi_{j}(h)\right)=h$ for any $h \in$ $L^{2}(0,1)$ and $\psi_{j}: L^{2}(0,1) \rightarrow W^{4}$ is bounded;

(E) $\bar{K}_{j}: L^{2} \rightarrow W^{3}$ defined by $\bar{K}_{j}=i \circ \psi_{j}$, where $i: D\left(L_{j}\right) \rightarrow W^{3}$ denotes the identity map, is compact.

The proof of (A)-(E) are direct and therefore omitted. For some of the estimates in (B), one needs to use Lemmas 2.2, 2.3, and 2.4.

3. Existence of solutions. In this section, we consider the solvability of the six boundary value problems consisting of the differential equation (1.1) in the following theorem.

THEOREM 3.1. Under the Assumptions (H1) and (H2), the boundary value problem consisting of (1.1), and $(1, j), j=2, \ldots, 7$, has at least one solution.

Proof. The boundary value problem (1.1) can be written as

$$
y=K_{j} y,
$$

where

$$
K_{j} y=\bar{K}_{j}\left[\lambda y^{\prime \prime}+k y+G\left(x, y, y^{\prime}, y^{\prime \prime}, y^{\prime \prime \prime}\right)-f\left(x, y, y^{\prime}, y^{\prime \prime}, y^{\prime \prime \prime}\right)\right]
$$


$K_{j}: W^{3} \rightarrow W^{3}$ is compact, and $\bar{K}_{j}$ is as in Lemma 2.5 . We prove the existence of solution of (3.1) by verifying the conditions of Lemma 1.1.

Assume that the solutions of $y-t K_{j} y=0$ are not uniformly bounded with respect to $t \in[0,1]$. Then there exist sequence $\left\{t_{n}\right\} \subset(0,1)$ and $y_{n} \in W^{3}$ such that

$$
y_{n}=t_{n} K_{j} y_{n}
$$

and $\left\|y_{n}\right\|_{3} \rightarrow \infty$ as $n \rightarrow \infty$.

From (3.3), it follows that each $y_{n}$ satisfies

$$
y_{n}^{\prime \prime \prime \prime}+t_{n} \lambda y_{n}^{\prime \prime}+t_{n} k y_{n}+t_{n} G\left(x, y_{n}, y_{n}^{\prime}, y_{n}^{\prime \prime}, y_{n}^{\prime \prime \prime}\right)=t_{n} f\left(x, y_{n}, y_{n}^{\prime}, y_{n}^{\prime \prime}, y_{n}^{\prime \prime \prime}\right)
$$

with $y_{n} \in D\left(L_{j}\right)$, which in turn implies (upon multiplying both sides of the equation by $y_{n}^{\prime \prime}$, integrating by parts and using the boundary conditions)

$$
\begin{aligned}
-\left\|y_{n}^{\prime \prime \prime}\right\|_{L^{2}}^{2}+t_{n} \lambda\left\|y_{n}^{\prime \prime}\right\|_{L^{2}}^{2}+t_{n} k \int_{0}^{1} y_{n} y_{n}^{\prime \prime} d x & +t_{n} \int_{0}^{1} G\left(x, y_{n}, y_{n}^{\prime}, y_{n}^{\prime \prime}, y_{n}^{\prime \prime \prime}\right) y_{n}^{\prime \prime} d x \\
& =t_{n} \int_{0}^{1} f\left(x, y_{n}, y_{n}^{\prime}, y_{n}^{\prime \prime}, y_{n}^{\prime \prime \prime}\right) y_{n}^{\prime \prime} d x .
\end{aligned}
$$

Set $z_{n}=y_{n} /\left\|y_{n}\right\|_{3}$, then $\left\{z_{n}\right\} \subset W^{3}$ is a bounded sequence, and since a bounded set of $W^{3}$ is weakly relatively compact, it follows that there exists a subsequence of $\left\{z_{n}\right\}$, that converges weakly in $W^{3}$. By the fact that the imbedding $i_{0}: D(L) \subset W^{3} \rightarrow C^{2}[0,1]$ is compact, it follows that there exists a subsequence of $\left\{z_{n}\right\}$, which we recall $\left\{z_{n}\right\}$ again, that converges strongly in $C^{2}[0,1]$ to some $z_{0} \in C^{2}[0,1]$.

From (3.5) and Assumption (H2), we obtain

$$
\begin{aligned}
-t_{n} \int_{0}^{1} g\left(y_{n}^{\prime \prime}\right) y_{n}^{\prime \prime} d x= & -\left\|y_{n}^{\prime \prime \prime}\right\|_{L^{2}}^{2}+t_{n} k \int_{0}^{1} y_{n} y_{n}^{\prime \prime} d x+t_{n} \lambda\left\|y_{n}^{\prime \prime}\right\|_{L^{2}}^{2} \\
& +t_{n} \int_{0}^{1} h\left(x, y_{n}, y_{n}^{\prime}, y_{n}^{\prime \prime}, y_{n}^{\prime \prime \prime}\right) y_{n}^{\prime \prime} d x \\
& -t_{n} \int_{0}^{1} f\left(x, y_{n}, y_{n}^{\prime}, y_{n}^{\prime \prime}, y_{n}^{\prime \prime \prime}\right) y_{n}^{\prime \prime} d x \\
\leq & t_{n}|k|\left\|y_{n}^{\prime \prime}\right\|_{L^{2}}\left\|y_{n}\right\|_{L^{2}}+t_{n}|\lambda|\left\|y_{n}^{\prime \prime}\right\|_{L^{2}}^{2} \\
& -t_{n} \int_{0}^{1} f\left(x, y_{n}, y_{n}^{\prime}, y_{n}^{\prime \prime}, y_{n}^{\prime \prime \prime}\right) y_{n}^{\prime \prime} d x \\
\leq & t_{n}\left(c_{j}^{-1}|k|+|\lambda|\right)\left\|y_{n}^{\prime \prime}\right\|_{L^{2}}^{2}+t_{n}\|\bar{f}\|_{L^{2}}\left\|y_{n}^{\prime \prime}\right\|_{L^{2}} .
\end{aligned}
$$

Using (3.6) and homogeneity of $g$, we obtain

$$
0 \leq-\int_{0}^{1} g\left(z_{n}^{\prime \prime}\right) z_{n}^{\prime \prime} d x \leq \frac{\left(c_{j}^{-1}|k|+|\lambda|\right)\left\|y_{n}^{\prime \prime}\right\|_{L^{2}}^{2}}{\left\|y_{n}\right\|_{3}^{p+1}}+\frac{\|\bar{f}\|_{L^{2}}\left\|y_{n}^{\prime \prime}\right\|_{L^{2}}}{\left\|y_{n}\right\|_{3}^{p+1}} \longrightarrow 0
$$

as $n \rightarrow \infty$. Since $g$ is continuous, it follows from (3.7) that $\int_{0}^{1} g\left(z_{0}^{\prime \prime}\right) z_{0}^{\prime \prime} d x=0$ which, in view of (H2) part (b), implies that $z_{0}^{\prime \prime}=0$. This together with the boundary conditions (1.2) through (1.7) imply that $z_{0}=0$. Thus $z_{n} \rightarrow 0$ in $C^{2}[0,1]$. 
On the other hand, from (3.5) we have

$$
\begin{aligned}
\frac{\left\|y_{n}^{\prime \prime \prime}\right\|_{L^{2}}^{2}}{\left\|y_{n}\right\|_{3}^{2}}= & t_{n} \lambda \frac{\left\|y_{n}^{\prime \prime}\right\|_{L^{2}}^{2}}{\left\|y_{n}\right\|_{3}^{2}}+t_{n} k \int_{0}^{1} \frac{y_{n} y_{n}^{\prime \prime}}{\left\|y_{n}\right\|_{3}^{2}} d x \\
& +t_{n} \int_{0}^{1} G\left(x, y_{n}, y_{n}^{\prime}, y_{n}^{\prime \prime}, y_{n}^{\prime \prime \prime}\right) \frac{y_{n}^{\prime \prime}}{\left\|y_{n}\right\|_{3}^{2}} d x \\
& -t_{n} \int_{0}^{1} f\left(x, y_{n}, y_{n}^{\prime}, y_{n}^{\prime \prime}, y_{n}^{\prime \prime \prime}\right) \frac{y_{n}^{\prime \prime}}{\left\|y_{n}\right\|_{3}^{2}} d x \\
\leq & t_{n} k\left[z_{n}^{\prime}(1) z_{n}(1)-z_{n}^{\prime}(0) z_{n}(0)\right]+t_{n} k \int_{0}^{1} z_{n}^{2} d x \\
& +t_{n} \lambda\left\|z_{n}^{\prime \prime}\right\|_{L^{2}}^{2}+t_{n} \frac{\|\bar{f}\|_{L^{2}}\left\|y_{n}^{\prime \prime}\right\|_{L^{2}}}{\left\|y_{n}\right\|_{3}^{2}}
\end{aligned}
$$

which implies that (by the fact that $z_{n} \rightarrow 0$ in $C^{2}[0,1]$ )

$$
\frac{\left\|y_{n}^{\prime \prime \prime}\right\|_{L^{2}}^{2}}{\left\|y_{n}\right\|_{3}^{2}} \longrightarrow 0
$$

However, from part (B) of Lemma 2.5 and Lemmas 2.2 and 2.3, we know that

$$
\left\|y_{n}\right\|_{L^{2}} \leq\left\|y_{n}^{\prime}\right\|_{L^{2}} \leq\left\|y_{n}^{\prime \prime}\right\|_{L^{2}} \leq\left\|y_{n}^{\prime \prime \prime}\right\|_{L^{2}} \text { for } y \in D(L)
$$

and moreover, we have

$$
\left\|y_{n}\right\|_{3}^{2}=\left\|y_{n}\right\|_{L^{2}}^{2}+\left\|y_{n}^{\prime}\right\|_{L^{2}}^{2}+\left\|y_{n}^{\prime \prime}\right\|_{L^{2}}^{2}+\left\|y_{n}^{\prime \prime \prime}\right\|_{L^{2}}^{2} \leq 4\left\|y_{n}^{\prime \prime \prime}\right\|_{L^{2}}^{2}
$$

and this contradicts (3.9). This completes the proof.

4. Uniqueness. Assume that $G\left(x, y, y^{\prime}, y^{\prime \prime}, y^{\prime \prime \prime}\right)$ and $f\left(x, y, y^{\prime}, y^{\prime \prime}, y^{\prime \prime \prime}\right)$ satisfy the condition (H3) for all $y, z \in W^{3}$,

$$
\begin{aligned}
\int_{0}^{1}\{ & {\left[G\left(x, y, y^{\prime}, y^{\prime \prime}, y^{\prime \prime \prime}\right)-f\left(x, y, y^{\prime}, y^{\prime \prime}, y^{\prime \prime \prime}\right)\right] } \\
& \left.-\left[G\left(x, z, z^{\prime}, z^{\prime \prime}, z^{\prime \prime \prime}\right)-f\left(x, z, z^{\prime}, z^{\prime \prime}, z^{\prime \prime \prime}\right)\right]\right\}\left(y^{\prime \prime}-z^{\prime \prime}\right) d x<0 .
\end{aligned}
$$

We obtain the following result on the uniqueness of the solution.

THEOREM 4.1. Assume (H3), the solution of the boundary value problem (1.1) has at most one solution, provided that $|\lambda| d_{j}^{2}+|k| c_{j}^{-1} d_{j}^{2} \leq 1$.

Proof. Let $y$ and $z$ be two solutions of the boundary value problem. Set $w=y-z$ and assume that $w^{\prime \prime} \neq 0, w$ satisfies the equation

$$
\begin{aligned}
w^{\prime \prime \prime \prime}+\lambda w^{\prime \prime}+k w+ & {\left[G\left(x, y, y^{\prime}, y^{\prime \prime}, y^{\prime \prime \prime}\right)-f\left(x, y, y^{\prime}, y^{\prime \prime}, y^{\prime \prime \prime}\right)\right] } \\
- & {\left[G\left(x, z, z^{\prime}, z^{\prime \prime}, z^{\prime \prime \prime}\right)-f\left(x, z, z^{\prime}, z^{\prime \prime}, z^{\prime \prime \prime}\right)\right]=0 }
\end{aligned}
$$

and the boundary condition (1.2) through (1.7). Let $A=\left\|w^{\prime \prime \prime}\right\|_{L^{2}}$ and $B=\left\|w^{\prime \prime}\right\|_{L^{2}}$. Upon multiplying (4.2) by $w^{\prime \prime}$ and integrating by parts, using the boundary conditions, Holder's inequality and (H3), we obtain

$$
-A^{2}+\lambda B^{2}+|k| c_{j}^{-1} B^{2}>0 .
$$


If $|\lambda| d_{j}^{2}+|k| c_{j}^{-1} d_{j}^{2} \leq 1$, we have

$$
\begin{aligned}
-A^{2}+\lambda B^{2}+|k| c_{j}^{-1} B^{2} & \leq-A^{2}+|\lambda| d_{j}^{2} A^{2}+|k| c_{j}^{-1} d_{j}^{2} A^{2} \\
& =A^{2}\left(-1+|\lambda| d_{j}^{2}+|k| c_{j}^{-1} d_{j}^{2}\right) \leq 0,
\end{aligned}
$$

where

$$
d_{j}= \begin{cases}\frac{1}{\pi}, & \text { for } j=2, \\ \frac{2}{\pi}, & \text { for } j=3,4,5,6,7,\end{cases}
$$

(see part (B) of Lemma 2.5). (4.4) contradicts the inequality (4.3).

Thus $w^{\prime \prime}=0$. This together with one of the boundary conditions (1.2), (1.3), (1.4), (1.5), (1.6), (1.7) imply that $w=0$. This proves the theorem.

REMARK 4.2. It is quite clear that most of the functions $G$ which are of interest physically satisfy our Assumptions (H2) parts (a), (b), and (c), and (H3). For example, $G(x, y, z, u, v)=-u^{3}$ satisfies all these assumptions. More generally, if we assume $c_{j} \in L^{2}(0,1), j=3,5, \ldots, 2 n+1$, are functions satisfying $c_{2 n+1}(x)<0$ and $c_{j}(x) \leq 0$ for $j=3,5, \ldots, 2 n-1$, then the functions $G(x, y, z, u, v)=c_{3}(x) u^{3}+c_{5}(x) u^{5}+\cdots+$ $c_{2 n+1}(x) u^{2 n+1}$ and $g(u)=c_{2 n+1}(x) u^{2 n+1}$ satisfy our Assumptions (H2) and (H3).

\section{REFERENCES}

[1] A. R. Aftabizadeh, C. P. Gupta, and J. Xu, Existence and uniqueness theorems for threepoint boundary value problems, SIAM J. Math. Anal. 20 (1989), no. 3, 716-726. MR 90e:34031. Zbl 704.34019.

[2] M. A. del Pino and R. F. Manásevich, Existence for a fourth-order boundary value problem under a two-parameter nonresonance condition, Proc. Amer. Math. Soc. 112 (1991), no. 1, 81-86. MR 91h:34027. Zbl 725.34020.

[3] M. B. M. Elgindi and Z. Guan, On the global solvability of a class of fourth-order nonlinear boundary value problems, Internat. J. Math. Math. Sci. 20 (1997), no. 2, 257-262. MR 98c:34031. Zbl 913.34020.

[4] C. P. Gupta, Existence and uniqueness theorems for the bending of an elastic beam equation, Appl. Anal. 26 (1988), no. 4, 289-304. MR 89m:34027. Zbl 611.34015.

[5]___ Existence and uniqueness theorems for some fourth order fully quasilinear boundary value problems, Appl. Anal. 36 (1990), no. 3-4, 157-169. MR 91e:34025. Zbl 713.34025 .

[6] R. Ma, Some multiplicity results for an elastic beam equation at resonance, Appl. Math. Mech. 14 (1993), no. 2, 193-200. MR 94e:34028. Zbl 776.73037.

[7] R. Ma, Z. Jihui, and F. Shengmao, The method of lower and upper solutions for fourth-order two-point boundary value problems, J. Math. Anal. Appl. 215 (1997), no. 2, 415-422. MR 98i:34037. Zbl 892.34009.

[8] R. Ma and H. Wang, On the existence of positive solutions of fourth-order ordinary differential equations, Appl. Anal. 59 (1995), no. 1-4, 225-231. MR 96m:34036. Zbl 841.34019.

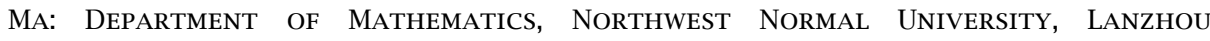
730070, GANSU, CHINA

E-mail address: mary@nwnu.edu.cn 


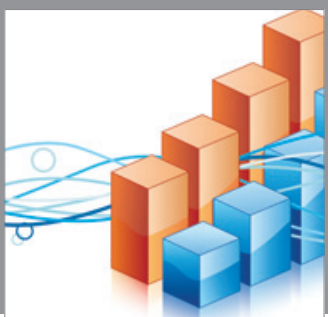

Advances in

Operations Research

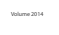

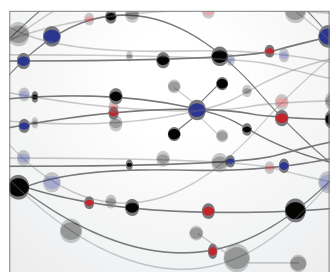

\section{The Scientific} World Journal
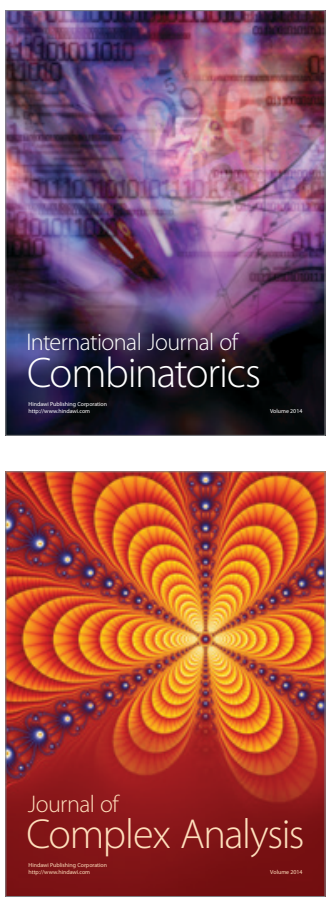

International Journal of

Mathematics and

Mathematical

Sciences
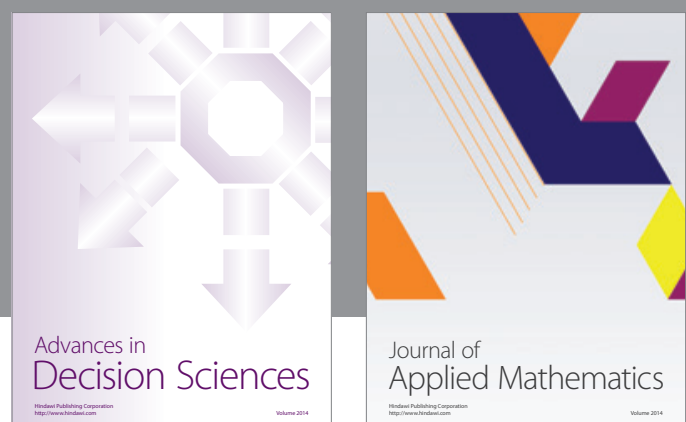

Journal of

Applied Mathematics
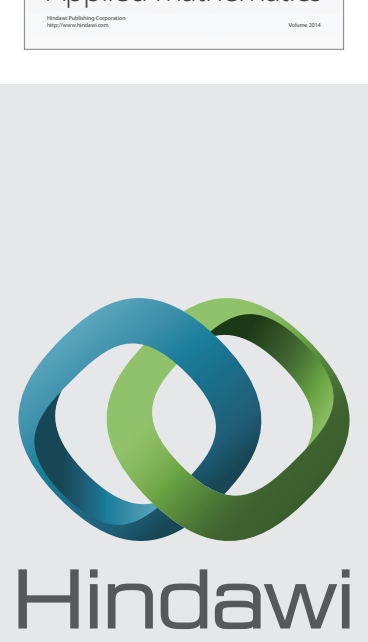

Submit your manuscripts at http://www.hindawi.com
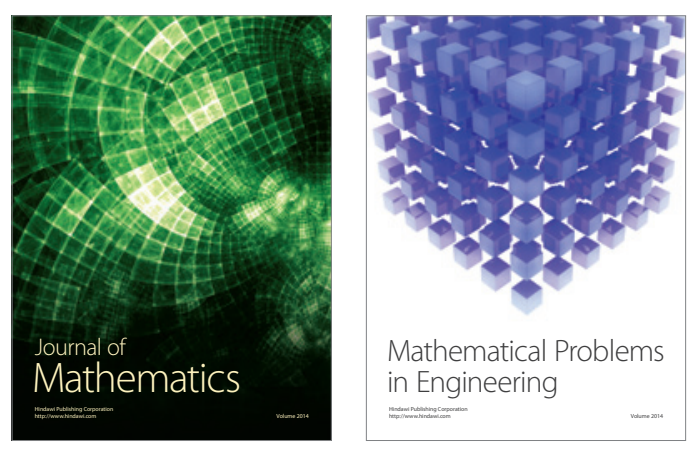

Mathematical Problems in Engineering
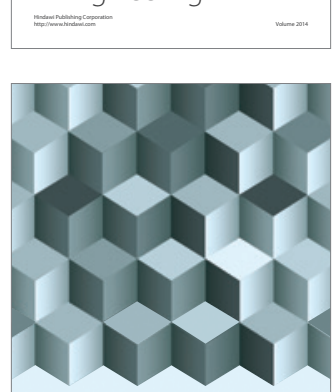

Journal of

Function Spaces
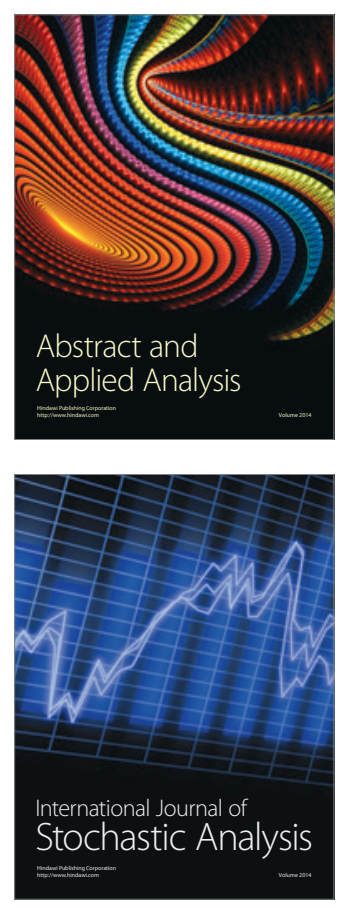

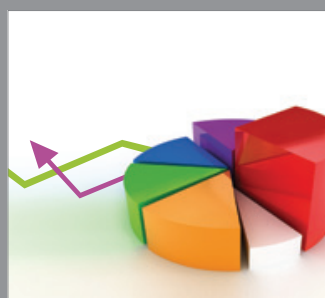

ournal of

Probability and Statistics

Promensencen
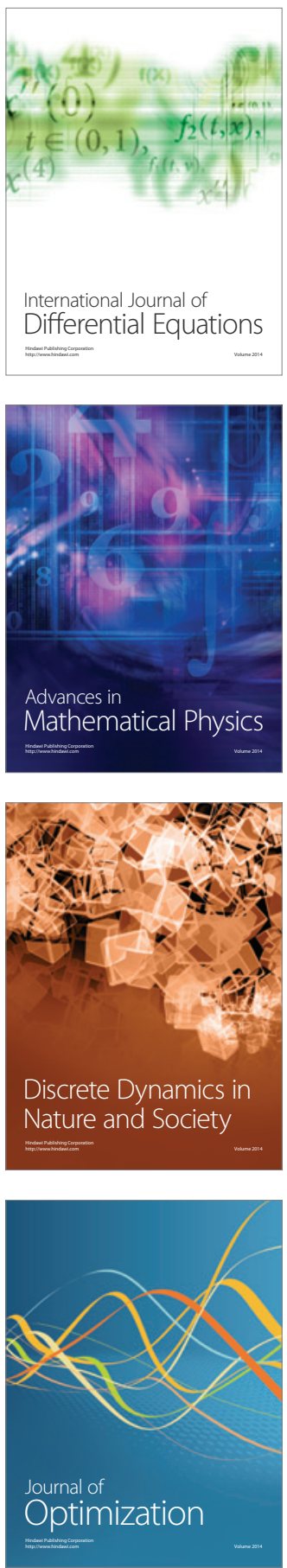